\section{Functional leaf traits and biodiversity effects on litter decomposition in a stream: reply}

MARK O. GesSNER ${ }^{1}$

Experiments testing for effects of litter mixing on decomposition have been an important component of efforts to elucidate the significance of biodiversity for ecosystem functioning. Outcomes of these experiments with mixed litter have been frustratingly mixed as well, however, with some suggesting positive effects on decomposition rate (i.e., acceleration), some negative effects, and some no effect at all (Gartner and Cardon 2004, Hättenschwiler et al. 2005, Gessner et al. 2010). How may these inconsistencies be reconciled? One idea is that diversity effects can arise only when functional traits of litter included in mixtures are sufficiently dissimilar to elicit litter-specific responses of microbial decomposers or detritivores (Hoorens et al. 2003, Smith and Bradford 2003, Epps et al. 2007, Schindler and Gessner 2009). Under this assumption, heterogeneous mixtures composed of dissimilar litter types are expected

Manuscript received 5 November 2009; accepted 3 December 2009. Corresponding Editor: P. M. Groffman.

${ }^{1}$ Department of Aquatic Ecology, Eawag: Swiss Federal Institute of Aquatic Science and Technology, 8600 Dübendorf, Switzerland; and Institute of Integrative Biology (IBZ), ETH Zurich, Switzerland. E-mail: gessner@eawag.ch to show strong diversity effects on decomposition. In contrast, decomposition of mixed litter composed of species that share functional traits (homogenous mixtures) is predicted not to deviate significantly from the average decomposition rate of component species. In light of the conflicting results from previous experiments (Gartner and Cardon 2004), we set out to test this hypothesis with litter from broad-leaved forest trees decomposing in a stream, and we concluded that our experiment provides some, but not overwhelming, support for the dissimilarity hypothesis (Schindler and Gessner 2009).

The commentary by Lecerf and Kominoski (2010) on our test of functional diversity as a predictor of decomposition in litter mixtures (Schindler and Gessner 2009) outlines ideal circumstances for conducting and analyzing such experiments, it expresses concern that our experiment and interpretations do not perfectly reflect these circumstances, and it suggests alternative ways to approach the question. I appreciate the comments by Lecerf and Kominoski (2010) and welcome the opportunity to respond. Below I will address each of the main concerns, reconcile or qualify apparent differences in appraisal, and clarify or justify our choices. In their concluding paragraph, Lecerf and Kominoski (2010) assert that their "primary objective is not to speculate on whether or not functional litter diversity is important in explaining decomposition." Overall, however, their commentary implies that clear diversity effects would have emerged in heterogeneous litter mixtures had we chosen a different "experimental design, data analysis, and interpretation" (Lecerf and Kominoski 2010). I will argue that this assertion is insufficiently substantiated and that our previous conclusions are well balanced and robust.

The most critical remark made by Lecerf and Kominoski (2010) relates to overlap in dissimilarity among litter types between our homogenous and heterogeneous litter mixtures. This observation is correct. Consequently, we explicitly discussed our results in light of this important point (Schindler and Gessner 2009). Lecerf and Kominoski (2010) enhance our discussion in that they make the argument quantitative by calculating functional diversity indices and comparing them statistically between our homogenous and heterogeneous litter mixtures. A limitation of this quantitative analysis is, however, that it ignores the specific pattern in our data set. Specifically, the overlap in dissimilarity we noted was primarily due to one fastdecomposing (alder) and one slow-decomposing (sycamore) litter species, which decomposed much more slowly or more rapidly, respectively, than suggested by previous results from the same (e.g., Hieber and Gessner 2002) or a similar (Gessner and Chauvet 1994) stream. Even so, alder litter behaved exactly as predicted for a fast-decomposing species under the dissimilarity hy- 
pothesis in that mass loss was faster in heterogeneous than in homogenous mixtures (Schindler and Gessner 2009: Fig. 5a). Ash, in contrast, showed identical decomposition rates in homogenous and heterogeneous mixtures. This is counter to expectations under the dissimilarity hypothesis because ash was unequivocally classified as a rapidly decomposing species. Thus, the species that caused overlap in functional dissimilarity between homogenous and heterogeneous litter mixtures (alder and sycamore) were not the same species responsible for our failure to detect unequivocal diversity effects on decomposition in the heterogeneous litter mixtures (e.g., ash). Therefore, although formally correct and generally useful, the functional diversity analysis by Lecerf and Kominoski (2010) falls short of elucidating the causes behind the outcome of our experiment. Clearly, overlap in dissimilarity between homogenous and heterogeneous litter mixtures was not the key driver accounting for the only marginally significant difference in decomposition rate observed by Schindler and Gessner (2009).

An important point to realize is that our experiment was not designed to maximize contrast among species in heterogeneous litter mixtures, and we avoided choosing litter from the regional species pool comprising different life forms. Instead the experiment was conceived to reflect the natural range of major litter types during autumn leaf fall in temperate forest ecosystems, including forest streams. As a consequence, our choice of litter was restricted to the relatively narrow range covered by leaves from broad-leaved deciduous trees. We also included species anticipated to decompose at intermediate rates, which reduces overall dissimilarity in heterogeneous litter mixtures. Greater contrasts between litter types can easily be created, for instance by mixing grasses and forbs (Hoorens et al. 2003), or by mixing litter of nitrogen-fixing species that have low concentrations of recalcitrant compounds with conifer needles containing high concentrations of lignin and other polyphenolics such as tannins (Fyles and Fyles 1993). If the dissimilarity hypothesis holds, then diversity effects are more likely detected in experiments involving only two such extreme end members than in the experiment reported in Schindler and Gessner (2009). Thus, it is certainly possible that clearer diversity effects arise in some heterogeneous litter mixtures than observed by Schindler and Gessner (2009), but the results of our experiment suggest that the underlying mechanisms may not be powerful enough to play out very strongly in litter mixtures from trees of temperate mixed deciduous forests.

Lecerf and Kominoski (2010) further argue that selection of discrete functional groups is inherently subjective (see also Petchey et al. 2009). They propose using instead continuous metrics that capture functional diversity, or dissimilarity, of species mixtures to increase chances of detecting functional diversity effects on ecosystem processes. This is a valid point. The suggestion boils down to substituting a continuous for a categorical variable and using regression analysis instead of analysis of variance. Although there is no doubt that such a regression approach could be powerful to test the dissimilarity hypothesis, it also poses its own inherent challenges. How to measure and express functional diversity on a continuous scale is an active area of research that is hotly debated at present. Deep disagreement exists about the metrics to use (e.g., Petchey and Gaston 2009, Poos et al. 2009) and, more important, effects of functional diversity on ecosystem processes hinge strongly on the traits selected to calculate functional diversity metrics (Petchy et al. 2009). Both realities introduce an element of subjectivity. It is in this light that we opted for the simplest possible, traditional approach and assigned leaf species to one of three well-established decomposition classes. This classification has been widely used since the seminal work on litter decomposition in streams by Petersen and Cummins (1974). Since the number of functional groups is fixed to three in this classification, our choice was not subjective, as Lecerf and Kominoski (2010) imply.

The final main point raised by Lecerf and Kominoski (2010) relates to statistical issues, particularly the fact that unbalanced experimental designs such as the one we used (Schindler and Gessner 2009) are less powerful than balanced designs. Unfortunately, the unbalanced design reflects the nature of litter mixing experiments, and of many biodiversity-ecosystem functioning experiments in general. This, together with other factors that reduce power of ANOVAs, could have influenced our ability to show litter heterogeneity to be a key driver of litter diversity effects on decomposition, as noted in Schindler and Gessner (2009). However, the argument of statistical power should not be overrated given that our design involved a total of 150 experimental units for the comparison of homogenous and heterogeneous litter mixtures, far more than in most ecological field experiments. In response to another statistical issue raised by Lecerf and Kominoski (2010), it is also important to clarify that our main conclusion (i.e., rather weak evidence for diversity effects on decomposition in heterogeneous litter mixtures) was primarily supported by the marginally significant $(P=0.06)$ interaction effect we obtained in an ANOVA (see Schindler and Gessner 2009: Table 4), reflecting the pattern shown in Fig. 5 of that paper. In contrast to the assertion by Lecerf and Kominoski (2010), we did not primarily base our argument on the percent of sums of squares accounted for by different factors in the ANOVA, although it is worth noting that the term of most interest, viz. the interaction between litter mixture (i.e., homogenous vs. heterogeneous mixture) and decay category (i.e., functional group), accounted for $<2 \%$ of 
the total variation in litter mass loss. Lecerf and Kominoski (2010) conclude their paragraph on statistical issues by stating that "extreme caution" is warranted "when interpreting nearly significant $P$ values." I concur. This is, therefore, precisely what we did.

The experiment presented in Schindler and Gessner (2009) represents one of the first attempts to explicitly test the dissimilarity hypothesis. It provides some hints in support of the hypothesis, but overall we found insufficient evidence to draw firm conclusions about the role of functional litter diversity in determining decomposition rates of litter mixtures. While I remain convinced that the conceptual basis and statistical approach of our study is sound and, especially, that the conclusions drawn are fully appropriate, I concede to Lecerf and Kominoski (2010) that many alternative ways can be envisaged to approach the problem of whether litter heterogeneity in mixtures determines the occurrence and strength of diversity effects on decomposition. One alternative is to measure trait dissimilarity of species mixtures based on a range of traits (e.g., lignin, nitrogen, and phosphorus concentrations) and use regression analysis to relate the average dissimilarity values of the mixtures to decomposition rate, as discussed above. In addition to such alternative experimental designs, specific tests may be conceived to elucidate possible biological mechanisms that could cause diversity effects on decomposition. So far, mechanisms underlying diversity effects on ecosystem processes have been largely explored by detecting patterns in data sets by computational means (Hector et al. 2009). This has yielded important insights. But greatest progress in the future will likely be made when the biological processes that lead to diversity effects are unraveled. Several such mechanisms have been identified (Hättenschwiler et al. 2005, Gessner et al. 2010) and await experimental testing.

\section{Acknowledgments}

I am grateful to Jessica Hines and Matty Berg for constructive comments and suggestions on the manuscript on short notice.

\section{Literature cited}

Epps, K. Y., N. B. Comerford, J. B. Reeves III, W. P. Cropper, Jr., and Q. R. Araujo. 2007. Chemical diversity highlighting a species richness and ecosystem function disconnect. Oikos 116:1831-1840.
Fyles, J. W., and I. H. Fyles. 1993. Interaction of Douglas-fir with red alder and salal foliage litter during decomposition. Canadian Journal of Forest Research 23:358-361.

Gartner, T. B., and Z. G. Cardon. 2004. Decomposition dynamics in mixed-species leaf litter. Oikos 104:230-246.

Gessner, M. O., and E. Chauvet. 1994. Importance of stream microfungi in controlling breakdown rates of leaf litter. Ecology 75:1807-1817.

Gessner, M. O., C. M. Swan, C. K. Dang, B. G. McKie, R. D. Bardgett, D. H. Wall, and S. Hättenschwiler. 2010. Diversity meets decomposition. Trends in Ecology and Evolution, in press.

Hättenschwiler, S., A. V. Tiunov, and S. Scheu. 2005. Biodiversity and litter decomposition in terrestrial ecosystems. Annual Review of Ecology, Evolution and Systematics 36:191-218.

Hector, A., T. Bell, J. Connolly, J. Finn, J. Fox, L. Kirwan, M. Loreau, J. McLaren, B. Schmid, and A. Weigelt. 2009. The analysis of biodiversity experiments: from pattern toward mechanism. Page 105-120 in S. Naeem, D. E. Bunker, A. Hector, M. Loreau, and C. Perrings, editors. Biodiversity, ecosystem functioning, and human wellbeing: an ecological and economic perspective. Oxford University Press, Oxford, $\mathrm{UK}$.

Hieber, M., and M. O. Gessner. 2002. Contribution of stream detrivores, fungi, and bacteria to leaf breakdown based on biomass estimates. Ecology 83:1026-1038.

Hoorens, B., R. Aerts, and M. Stroetenga. 2003. Does initial litter chemistry explain litter mixture effects on decomposition? Oecologia 137:578-586.

Lecerf, A., and J. Kominoski. 2010. Functional leaf traits and biodiversity effects on litter decomposition in a stream: comment. Ecology 91:1867-1869.

Petchey, O. L., and K. J. Gaston. 2009. Dendrograms and measures of functional diversity: a second installment. Oikos 118:1118-1120.

Petchey, O. L., E. J. O’Gorman, and D. F. B. Flynn. 2009. A functional guide to functional diversity. Page $49-59$ in S. Naeem, D. E. Bunker, A. Hector, M. Loreau, and C. Perrings, editors. Biodiversity, ecosystem functioning, and human wellbeing: an ecological and economic perspective. Oxford University Press, Oxford, UK.

Petersen, R. C., and K. W. Cummins. 1974. Leaf processing in a woodland stream. Freshwater Biology 4:343-368.

Poos, M. S., S. C. Walker, and D. A. Jackson. 2009. Functional-diversity indices can be driven by methodological choices and species richness. Ecology 90:341-347.

Schindler, M. H., and M. O. Gessner. 2009. Functional leaf traits and biodiversity effects on litter decomposition in a stream. Ecology 90:1641-1649.

Smith, V. C., and M. A. Bradford. 2003. Do non-additive effects on decomposition in litter-mix experiments result from differences in resource quality between litters? Oikos 102: 235-242. 